\title{
Acute Effects of Work Rest Interval Duration of 3 HIIT Protocols on Cycling Power in Trained Young Adults
}

\author{
José Manuel García-De Frutos ${ }^{1}$, Fco. Javier Orquín-Castrillón ${ }^{1}$, Pablo Jorge Marcos-Pardo ${ }^{2,3}$ [D, \\ Jacobo Á. Rubio-Arias ${ }^{2}\left(\mathbb{D}\right.$ and Alejandro Martínez-Rodríguez ${ }^{4,5, *(1)}$
}

1 Physical Activity and Sport Sciences Department, Faculty of Sport, Catholic University San Antonio of Murcia, 30107 Murcia, Spain; defrutos60@gmail.com (J.M.G.-D.F.); forquin@ucam.edu (F.J.O.-C.)

2 Department of Education, Faculty of Education Sciences, University of Almería, 04120 Almería, Spain; pjmarcos@ual.es (P.J.M.-P.); jararias@ual.es (J.Á.R.-A.)

3 SPORT Research Group (CTS-1024), CERNEP Research Center, University of Almería, 04120 Almería, Spain

4 Department of Analytical Chemistry, Nutrition and Food Sciences, Faculty of Science, Universidad de Alicante, 03690 Alicante, Spain

5 Alicante Institute for Health and Biomedical Research (ISABIAL Foundation), 03010 Alicante, Spain

* Correspondence: amartinezrodriguez@ua.es

Citation: García-De Frutos, J.M.; Orquín-Castrillón, F.J.; Marcos-Pardo, P.J.; Rubio-Arias, J.Á.; MartínezRodríguez, A. Acute Effects of Work Rest Interval Duration of 3 HIIT Protocols on Cycling Power in Trained Young Adults. Int. J. Environ. Res. Public Health 2021, 18, 4225. https://doi.org/10.3390/ijerph180 84225

Academic Editor: Panagiota

(Nota) Klentrou

Received: 9 March 2021

Accepted: 13 April 2021

Published: 16 April 2021

Publisher's Note: MDPI stays neutral with regard to jurisdictional claims in published maps and institutional affiliations.

Copyright: (c) 2021 by the authors. Licensee MDPI, Basel, Switzerland. This article is an open access article distributed under the terms and conditions of the Creative Commons Attribution (CC BY) license (https:/ / creativecommons.org/licenses/by/ $4.0 /)$.

\begin{abstract}
High-Intensity Interval Training (HIIT) is described as a succession of short duration and maximum or near-maximum intensity efforts, alternated by recovery periods during which exercise continues at a lower intensity (active recovery) or is interrupted (passive recovery). Our objective was to evaluate the acute responses of three HIIT protocols of different work/rest interval times over the total time of the session, with self-selectable load and up to exhaustion, "all out".The sample was composed of 22 male participants $(n=22)$ between 19 and 24 years old. The HIIT protocol consisted of one of the three HIIT protocols, of 30,60 and 90 s density ratio 1:1 and with passive rest, with a total exercise duration of $10 \mathrm{~min}$. The test was performed in a cycloergometer set in workload mode independent of the pedaling frequency. The comparison of the three HIIT protocols shows that the duration of the work/rest intervals, starting from $30 \mathrm{~s}$ of work, in the cycloergometer, there are no significant differences in the levels of lactate concentration in the blood, nor in the heart rate, since a similar amount is obtained in the three protocols. The percentage of maximum power developed reached in each HIIT protocol is related to the duration of the working intervals.
\end{abstract}

Keywords: power loss; blood lactate concentration; youth; athletic performance

\section{Introduction}

High-intensity interval training (HIIT) is a training method currently considered one of the most effective in improving cardiorespiratory and metabolic function [1]. HIIT can be defined as repeated bouts of high intensity exercise, from a maximum lactate steady state (MLSS) respiratory compensation point (CPR) to a total supramaximal exercise intensity, interspersed with periods of recovery from low or moderate intensity exercise (active recovery) or complete rest [2]. Due to these recovery phases, peak workloads can be sustained for a longer cumulative period than in a period of continuous exercise [3].

In addition, HIIT is considered the most effective training modality to improve cardiorespiratory and metabolic functioning and, in turn, endurance performance [1] since this exercise modality allows individuals to perform a greater volume of exercises at high intensity, than do continuous exercises [4,5]. With exercises at these intensities, the oxygen delivery and utilization systems are under maximal stress, which may provide the most effective stimulus for increasing maximum oxygen uptake (VO2max) $[1,6]$.

According to Seiler [7] the intensity of exercise can be divided into three zones: exercise intensity zone 1 , which corresponds to an intensity with minimal accumulation of lactate in the blood, zone 2, which corresponds to an intensity with accumulation of lactate in 
the blood (below the lactate threshold (LT) or ventilatory threshold (VT)), but with a rate in the exercise that remains sustainable with effort (below maximal lactate steady state (MLSS) / onset of blood lactate accumulation (OBLA)), and zone 3, which corresponds to an intensity that cannot be maintained for more than $5 \mathrm{~min}$, and therefore we define it as HIIT. However, the goal of HIIT is defined as increasing the training time close to VO2max, thus producing a stronger stimulus for cardiovascular health and muscle adaptations [1].

The prescription of a HIIT consists of the manipulation of up to nine variables including intensity and duration of the work interval, intensity of the recovery interval, and duration, type of exercise, number of intervals, time of series, recovery between series duration and intensity. The manipulation of any of them can affect the acute physiological responses of the subject [1]. Currently, the scientific community shows a diversity of HIIT methods applied in different studies, with different types of samples and protocols which suggest that the acute physiological mechanisms during HIIT are not clear, or that all their possibilities are not taken into account [8]. The degree of these acute physiological responses is strongly influenced by the specific prescription of single exercise, components such as intensity and duration of peak workload and recovery phases [7], although isolated manipulation of a single variable during exercise can have a direct impact on acute metabolic, cardiopulmonary and neuromuscular responses [7] it is the acute physiological response that largely determines the particular muscular and systemic training adaptations $[9,10]$

Consequently, a consistent prescription model is needed to regulate and predict the acute physiological responses of HIIT [11]. Interval training protocols can be divided into two categories, based on intensity-based exercise [12]: HIIT, performed at intensities between $80 \%$ and $100 \%$ of maximum work capacity interspersed with periods of low active recovery intensity of 1 to $4 \mathrm{~min}$, and SIT, characterized by total intervals at intensities of $100 \%$ of maximum work capacity interspersed with 2-4 min of low intensity active/passive recovery.

Despite the growing number of research studies employing protocols varying from submaximal intensity (HIIT) to supramaximal intensity (SIT), little is known about physiological and psychological responses. Understanding how HIIT and SIT protocols that vary in work/rest ratio and intensity differentially influence psychophysiological responses is essential to effectively prescribe HIIT and SIT for both health/fitness and performance training [13].

However, methodological issues such as small sample size, short intervention period, and/or matching training regimen to total energy expenditure make it difficult to compare results [14].

Therefore, it is imperative for fitness professionals that physiological responses to various protocols and populations are characterized so that HIIT can be safely prescribed [15]. Even less is known about the acute response in different "all out" HIIT protocols participants must require to self-select their exercise intensity in response to "interval and maximal effort session" [16-18] protocols of the same duration, but with different working time, specifically in young active men.

The purpose of this study was to compare the pre-post acute response of 3 protocols of different work time duration, but with the same total work time, in young men active on bicycle ergometers. This objective was to test the hypothesis that the longer the work duration, the lower the acute response in testing.

\section{Materials and Methods}

\subsection{Study Design}

A cross-over design study was conducted with an experimental group where participants completed 3 counterbalanced HIIT sessions at 3 different times, developed one per week (see Figure 1). The study followed the ethical research standards as established in the Declaration of Helsinki and was approved by the local ethical committee (San Antonio Catholic University of Murcia, Spain) with the code: C8061811. 


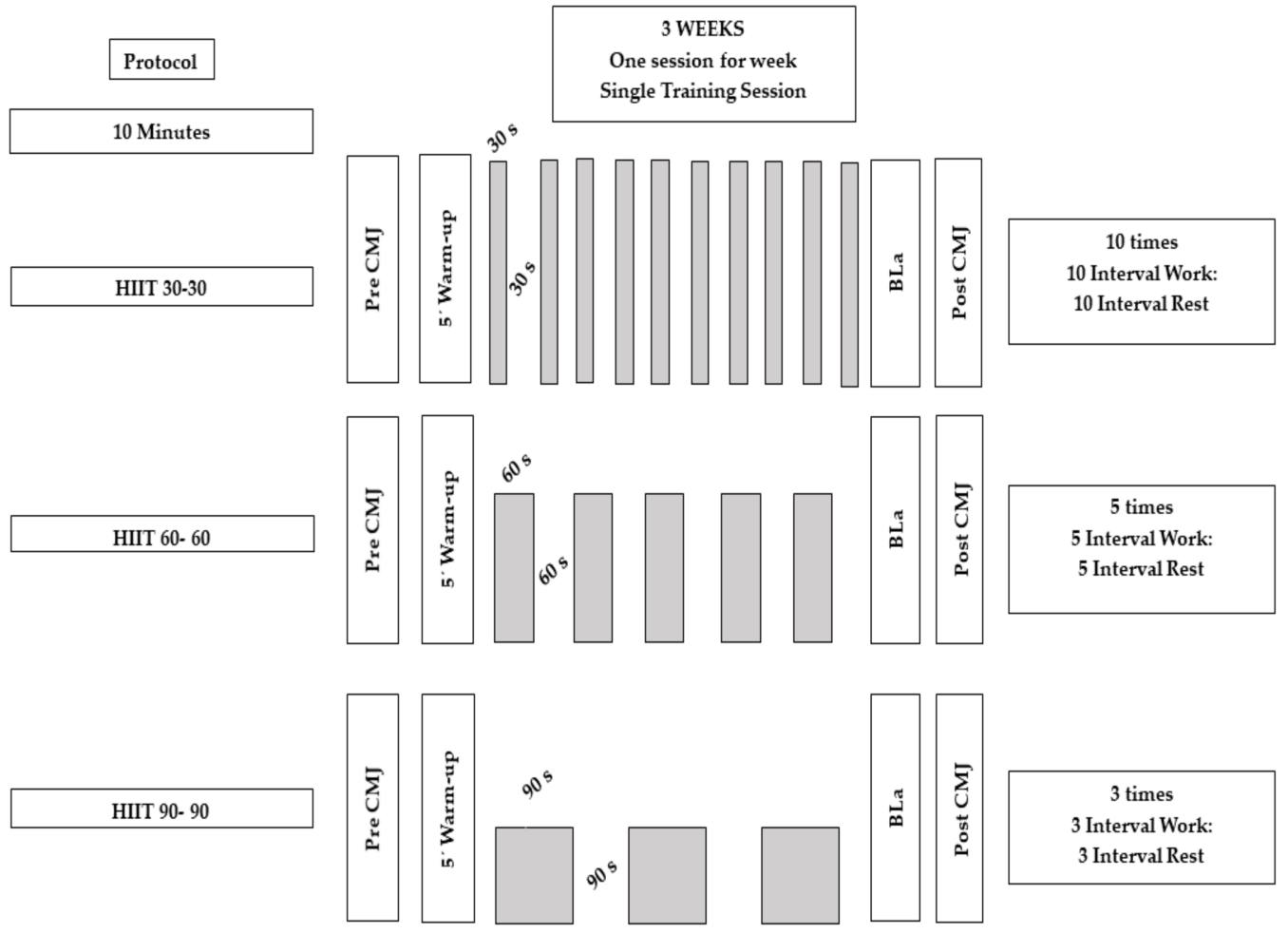

Figure 1. Scheme of the training sessions. $\mathrm{BLa}=$ Lactate $\mathrm{CMJ}=$ Counter movement jump.

\subsection{Participants}

Twenty-two young men (mean age: $21 \pm 2.0$ years; body weight: $70.6 \pm 11.1 \mathrm{~kg}$; body height: $174.2 \pm 9.9 \mathrm{~cm}$; body mass index: $24.7 \pm 1.7 \mathrm{~kg} / \mathrm{m}^{2}$; HIT training experience: 1 year, training: $2 \mathrm{~h}$ /week) had previous experience with high-intensity training. All-out concept was introduced as maximum effort developed and maintained for the time of work. The inclusion criteria in the study were physically active experts in the HIIT training method. The inclusion criteria in the study were: (1) being between 18 and 25 years old, (2) being active according to the American College of Sports Medicine (ACSM) definition [19], (3) having experience of more than 6 months of training in HIIT method, and (4) training systematically with the HIIT method. The exclusion criteria were: (1) ingesting any type of pharmacological treatment that may influence the performance (improvement or decline) of the subject, (2) performing other physical activities with overload that may influence the results of the study during participation, and (3) not respecting the training guidelines dictated in the study. All participants gave their informed written consent to participate in the research.

Participants were instructed to avoid exercising for a minimum of $24 \mathrm{~h}$ and consuming alcoholic beverages for a minimum of $48 \mathrm{~h}$ prior to testing. An initial information session was held during which were detailed the study design (including the study objectives) and the dates of the pre- and post-intervention evaluations. During this session, the testing protocol and the intervention plan were detailed to the participants. The intervention program took place once a week for three weeks in a row.

\subsection{Training Intervention}

Training interventions (every single session) were supervised by professional sport scientists. The experimental group (EG) had to carry out 3 supervised training sessions. Such sessions took place on the same day of the week once a week and chronologically followed an established order. Each session lasted about $40 \mathrm{~min}$. The same warm-up was performed in all sessions, consisting of $5 \mathrm{~min}$ of continuous pedaling on the cycle ergometer, at $100 \mathrm{~W}$, with $1 \mathrm{~min}$ of rest [7]. 
The 3 protocols of the intervention consisted of a HIIT session of 30, 60, and $90 \mathrm{~s}$, respectively. The 3 protocols held the same 1: 1 density, passive rest, and total duration of $10 \mathrm{~min}$. An electronically controlled cycle ergometer (Technogym Bike Med Technogym SpA, Cesena, Italy) was employed, with a workload mode independent of pedaling frequency [14]. In all protocols, subjects had to self-select their exercise intensity in response to a prescription of "effort maximum interval and session" [14]. Participants were instructed to remain seated on the cycle ergometer during the test.

In total, 10, 5, or 3 high intensity intervals were performed according to the protocol of $30 \mathrm{~s}, 60 \mathrm{~s}$, or $90 \mathrm{~s}$, respectively, analyzing the maximum power (Pmax), average power (Pmean), and power loss (Ploss), all measured in watios (W) between intervals, taking the value of said power every $5 \mathrm{~s}$ during the HIIT work intervals. All 22 participants completed the 3 sessions without incidents.

\subsection{Anthropometric Measurements}

Anthropometric measurements were performed in fasting conditions. Height $(\mathrm{cm})$ and body mass $(\mathrm{kg})$ were assessed using a digital balance and portable stadiometer. Body mass index (BMI) was calculated using the equation "body mass $(\mathrm{kg}) /$ height $(\mathrm{cm})^{2}$ ".

\subsection{Physical Measurements Control}

Heart rate (HR) and blood lactate concentration (BLa) levels were used as indicators of the intensity of the test. HR was measured continuously by analyzing the mean in each work interval by telemetry (Polar H7, Beth Page, NY, USA) in all sessions, during the test time. After a 1-min rest, capillary BLa was measured with the enzymatic amperometric method using the Lactate Scout system (RedMed, Warsaw, Poland). The test range for the method was $0.5-25 \mathrm{mmol} / \mathrm{L}$. The tip of the index finger was washed with a wet paper towel and dried, and the lactate concentration was measured using the second drop of blood, since the first drop was removed.

\subsection{Physical Measurements Experimental}

In order to obtain indicators of the subject's performance in each of the HIIT protocols, the explosive force of the lower body was measured, by comparing the maximum height reached in the performance of a Counter Movements Jump (CMJ) test [20], pre and post completion of each HIIT protocol, using the MuscleLab force platform (Ergotest Technology AS, Porsgrunn, Norway) and data collection of the different results of the power achieved on the cycle ergometer during each interval of each HIIT protocol. Pmax, Pmean, and Ploss were all measured in watios (W).

\subsection{Statistical Analysis}

For statistical analysis, the IBM SPSS Statistics for Windows program in version 25.0 (Armonk, NY: IBM Corp.) was used. Descriptive statistics were reported as mean \pm standard deviation. Preliminary analyses included checking assumptions such as normality, homogeneity of variances. No violations of the normality of the data were observed in the Kolmogorov-Smirnov test, which led to the use of parametric statistics. The homogeneity of the variances was carried out using Levene's test. Likewise, all variables were analyzed according to the two-way ANOVA test (time: before or after; and protocol) to examine whether there were statistically significant differences in these types of variables between the protocols.

However, in relation to the development of power in each of the protocols, independently, a comparison was carried out between the different intervals that made up each of the protocols by means of a repeated measures ANOVA. For all variables, the level of statistical significance was established at $p \leq 0.05$, with a $95 \%$ confidence interval for

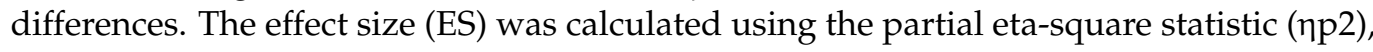
considered greater than 0.8 , between 0.8 and 0.5 , between 0.5 and 0.2 , and less than 0.2 were considered large, moderate, small, and trivial, respectively [21]. 


\section{Results}

In the results obtained in the physical control measurements, in blood lactate concentration level, no significant differentiation was observed when the lactic acid concentration was compared at the three protocols $(\mathrm{F}=1000 ; p=0.337 ; \eta \mathrm{p} 2=0.031)$. On the other hand, in the variable of the mean heart rate, there were significant differences $(\mathrm{F}=10.344$; $p=0.000 ; \eta p 2=0.247)$ between the $30 \mathrm{~s}$ vs. 90 s protocols $(p<0.001 ; 95 \% \mathrm{CI}=(4.5286-14.6533)$; $\eta \mathrm{p} 2=0.247)$. Table 1 shows the physiological control parameters chosen at the baseline for the 3 different training protocols, whereas Table 2 presents the experimental physiological parameters chosen at the baseline.

Table 1. Physiological control parameters chosen at the baseline for the 3 different training protocols.

\begin{tabular}{|c|c|c|c|c|c|c|c|}
\hline $\begin{array}{l}\text { Protocol High-Intensity } \\
\text { Interval Training (HIIT) }\end{array}$ & \multicolumn{2}{|c|}{$30 \mathrm{~s}$} & \multicolumn{2}{|c|}{$60 \mathrm{~s}$} & \multicolumn{2}{|c|}{$90 \mathrm{~s}$} & \multirow[b]{2}{*}{ Sig. } \\
\hline PMC & $X$ & SD & $X$ & SD & $X$ & SD & \\
\hline LA (mmol/L) & 16.6 & \pm 0.6 & 15.9 & \pm 0.6 & 17.1 & \pm 0.60 & 0.373 \\
\hline $\mathrm{HR}_{\text {mean }}(\mathrm{b} / \mathrm{min})$ & 175.4 & \pm 8.4 & 170.7 & \pm 6.2 & 165.8 & \pm 6.06 & $<0.001$ \\
\hline
\end{tabular}

$>$ HIIT = high intensity interval training, PMC = Physical measurements control, $\mathrm{X}=$ mean; SD = standard deviation; BLa = blood lactate concentration, HRmean = mean heart rate.

Table 2. Experimental physiological parameters chosen at the baseline for the 3 different training protocols.

\begin{tabular}{|c|c|c|c|c|c|c|c|}
\hline \multirow{2}{*}{$\begin{array}{c}\text { Protocol HIIT } \\
\text { PME }\end{array}$} & \multicolumn{2}{|c|}{$30 \mathrm{~s}$} & \multicolumn{2}{|c|}{$60 \mathrm{~s}$} & \multicolumn{2}{|c|}{$90 \mathrm{~s}$} & \multirow[b]{2}{*}{ Sig. } \\
\hline & $x$ & SD & $x$ & SD & $x$ & SD & \\
\hline $\begin{array}{c}\text { IA } \\
\mathrm{CMJ}(\mathrm{cm})\end{array}$ & -4.6 & \pm 3.3 & -3.8 & \pm 3.6 & -3.75 & \pm 3.6 & 0.682 \\
\hline $\begin{array}{c}\mathrm{IW} \\
\mathrm{CMJ}(\mathrm{W} / \mathrm{kg})\end{array}$ & -2.9 & \pm 2.5 & -2.8 & \pm 2.9 & -2.37 & \pm 4.1 & 0.832 \\
\hline $\mathrm{P}_{\max }(\mathrm{W})$ & 531.7 & \pm 168.9 & 481.9 & \pm 139.2 & 355.6 & \pm 104.7 & $<0.001$ \\
\hline$P_{\text {mean }}(W)$ & 312.6 & \pm 60.7 & 247.2 & \pm 54.1 & 223.4 & \pm 52.9 & $<0.001$ \\
\hline $\mathrm{P}_{\text {loss }}(\mathrm{W})$ & -246.0 & \pm 188.5 & -262.9 & \pm 145.3 & -160.8 & \pm 68.8 & 0.047 \\
\hline
\end{tabular}

$\mathrm{HITT}=$ high intensity interval training, $\mathrm{PME}=$ Physical measurements experimental, $\mathrm{X}=$ mean; $\mathrm{SD}=$ standard deviation; IA CM J = increase height jump against movement, IW CM J = increased power jumping against movement, $\operatorname{Pmax}(\mathrm{W})=$ maximum power, Pmean $(\mathrm{W})=$ mean power, Ploss $(\mathrm{W})=$ loss power.

The results found for the experimental physical measurements show no significant differences in the increase in height in the CMJ when the three HIIT protocols were compared $(\mathrm{F}=0.385 ; p=0.682 ; \eta p=0.012)$. For increased power in the $\mathrm{CMJ}$, no significant differences were found when the three protocols were compared $(\mathrm{F}=0.185 ; p=0.832$; $\eta p 2=0.006$ ).

Regarding the power developed during the 3 protocols (see Figure 2), significant differences were found in the maximum power $(\mathrm{F}=9.237 ; p<0.001 ; \eta p 2=0.227)$. In the comparison between the protocols, there were significant differences between the $30 \mathrm{~s}$ vs. $90 \mathrm{~s}$ groups $(p<0.001)$ of the multiple comparison $(p<0.001$; $\eta \mathrm{p} 2=0.227$; $95 \% \mathrm{CI}=(74.7252-277.5475))$. There were also significant differences between the 90 $\mathrm{s}$ vs. $60 \mathrm{~s}$ protocols $(p=0.011 ; \eta \mathrm{p} 2=0.227 ; 95 \% \mathrm{CI}=(-227.7293--24.9071)$.

In the mean power (Figure 3), significant differences were found when the three protocols were compared $(\mathrm{F}=14.926 ; p<0.001 ; \eta \mathrm{p} 2=0.322)$. In the comparison between the protocols, significant differences were found between groups 30 and $60 \mathrm{~s}(p=0.001)$ of the multiple comparison $(p<0.001 ; \eta p 2=0.322 ; 95 \% \mathrm{CI}=(24.7917-105.9356))$ and between protocols 30 and $90 \mathrm{~s}(p<0.001)$ of the multiple comparison $(p<0.001 ; \eta p 2=0.322$; $\mathrm{CI} 95 \%=(48.6098-129.7538))$. 


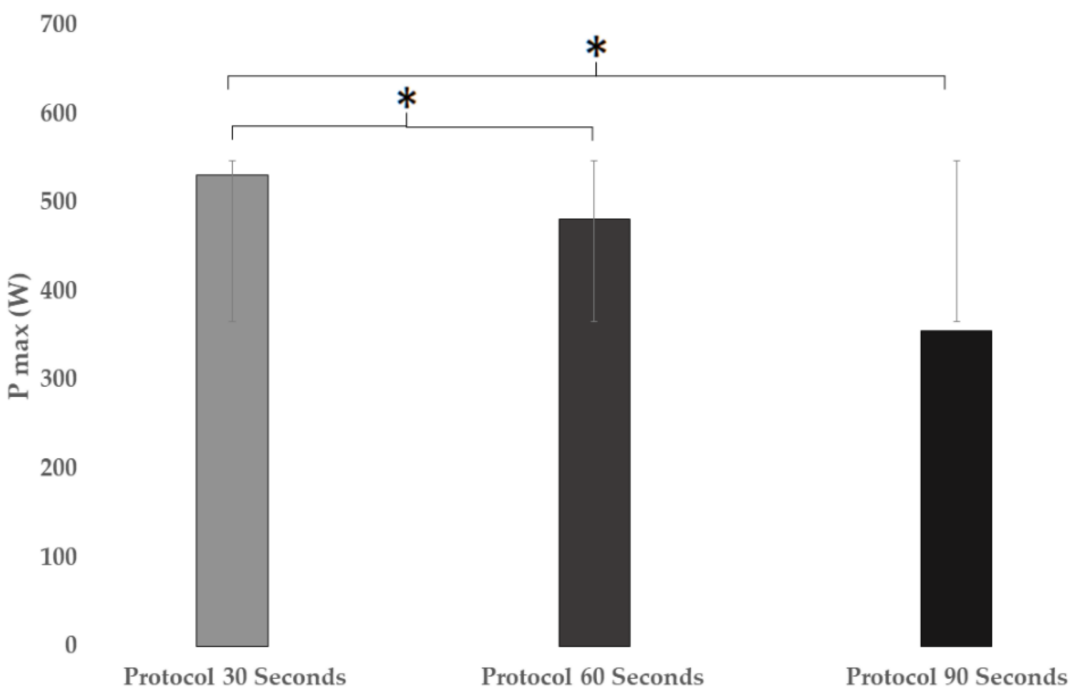

Figure 2. Comparison of maximum power developed in different High-Intensity Interval Training (HIIT) protocols. ${ }^{*}$ means significant difference.

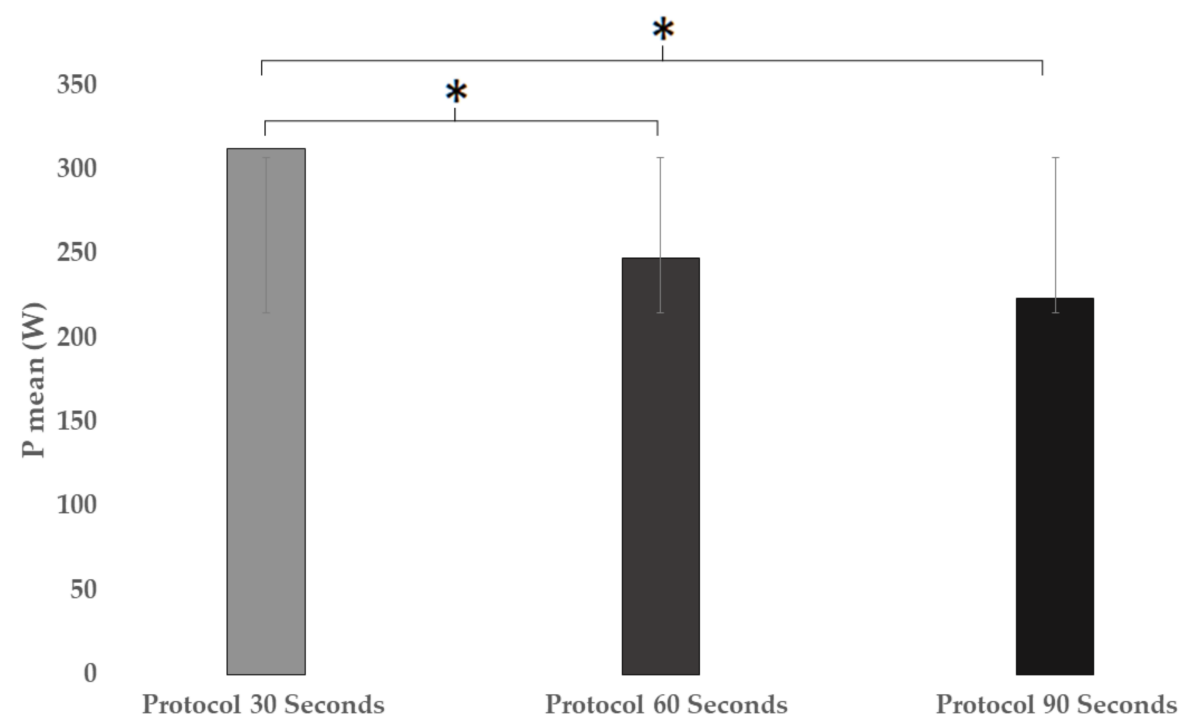

Figure 3. Average power comparison developed in different HIIT protocols. ${ }^{*}$ means significant difference.

In the variable of lost power (Figure 4), significant differences were found when the three protocols were compared $(\mathrm{F}=3.217 ; p=0.047 ; \eta \mathrm{p} 2=0.093)$. In the comparison between the protocols, there was a significant difference between 60 and 90 s protocols $\left(p=0.045^{*}\right)$ of the multiple comparison $\left(p=0.047^{*} ; \eta p 2=0.093 ; 95 \% \mathrm{CI}=(-205.6400-1.4582)\right.$. 


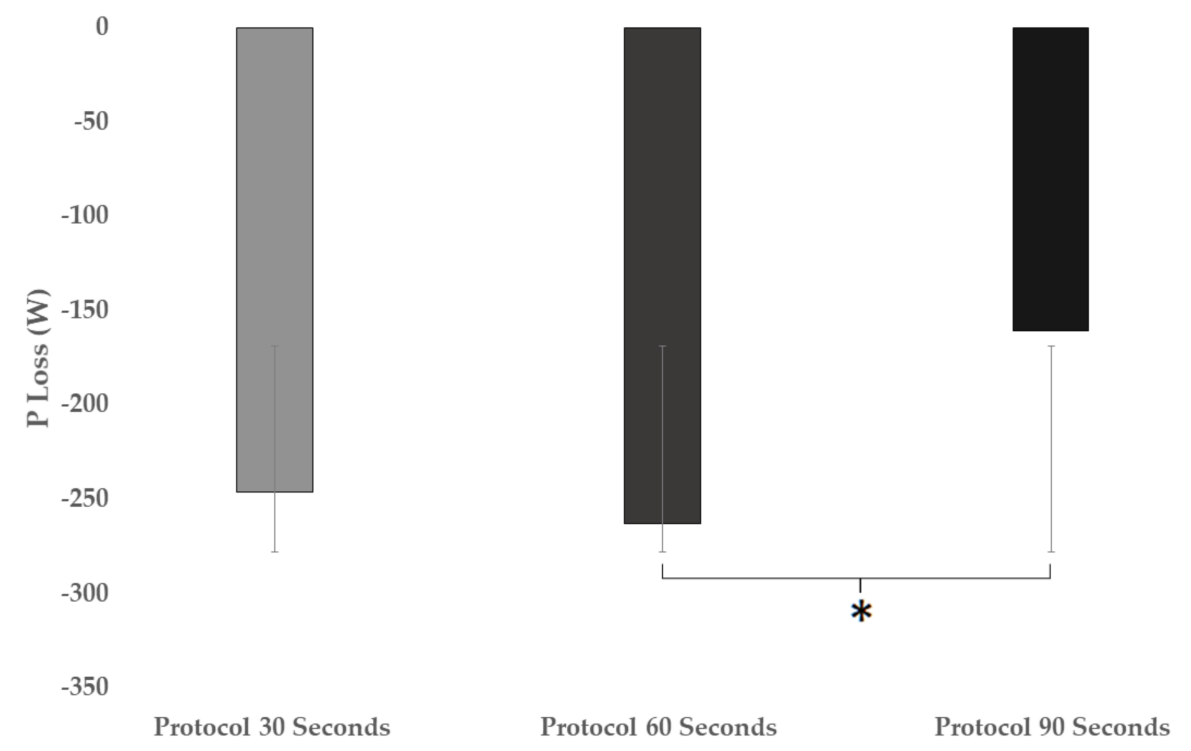

Figure 4. Loss power comparison developed in different HIIT protocols. * means significant difference.

Regarding Figure 5, the \% of the maximum power developed, significant differences were found when comparing the three protocols $(\mathrm{F}=7.991 ; p=0.001 ; \eta p 2=0.202)$. Such comparison manifested a significant difference between the 30 and $90 \mathrm{~s}$ protocols $(p=0.001 *)$ of the multiple comparison $(p=0.001 * ; \eta p 2=0.202 ; 95 \% \mathrm{CI}=(0.0601-0.2417))$.

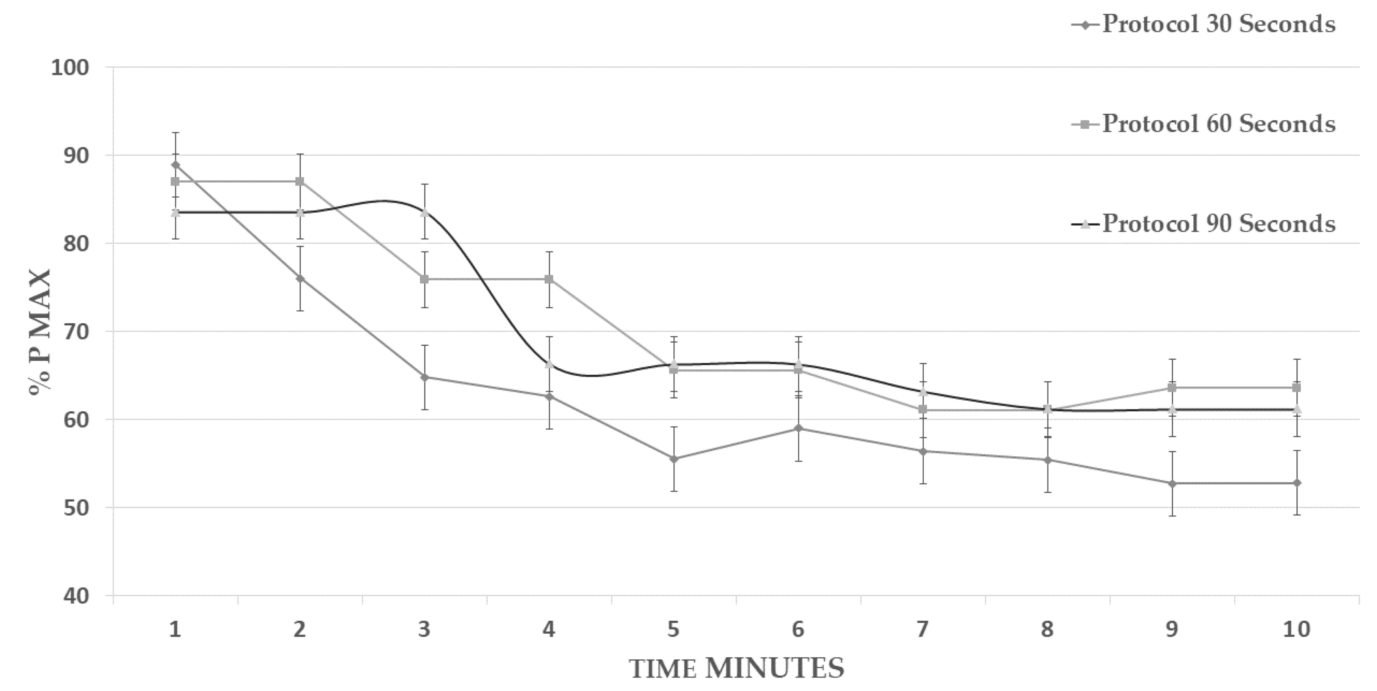

Figure 5. Development of maximum power of the different HIIT protocols.

\section{Discussion}

Due to the increasing popularity of HIIT, we wanted to analyze how protocols that vary in work/rest ratio and intensity influence physical responses, as they could be critical to effectively prescribing HIIT according to the training goal. In the BLa, there was no difference between the results at the end of the test in the three protocols (Table 2). Rønnestad [16] obtained results of a certain nature similar to ours, showing that two HIIT of different work/rest time, both short HIIT, $30 \mathrm{~s}$ of work and 15-s rest, and long HIIT, 5 min of work and 4-min rest with a goal of maximum effort, did not show differences regarding the production of BLa concentration at the end of the test. In line with these results, Tucker et al. [22], using two different protocols of 4-min intervals at 90-95\% RH, separated by a 3-min recovery, and 16 1-min intervals at $90-95 \%$ of HR, separated by a recovery of $1 \mathrm{~min}$, did not observe differences in the concentrations of Bla in blood at 
the end of the HIIT protocol (10.6 \pm 1.5 vs. $10.6 \pm 2.4$ mmol-L); therefore, from $30 \mathrm{~s}$ of maximum intermittent effort, the Bla levels will possibly be similar regardless of the total work time.

Regarding HR, it has been observed that there were no differences between our protocols. Razanek et al. [23] also obtained similar results in the comparison between their protocols HR max (182.1 \pm 6.2) and the same as Follador et al. [13] who compared 2 protocols of 10 intervals, one at $60 \mathrm{~s} / 60 \mathrm{~s} \mathrm{HR} \max (150 \pm 11.2)$ with another of $20 \mathrm{~s} / 10 \mathrm{~s}$ with a HR $(156.7 \pm 11.9$.) Furthermore, Patrick et al. [24] in their study obtained similar results regarding HR max between the HIIT protocols of 90 and $95 \%$ of HR max. HRmax has been shown to decrease in adaptation to resistance training [25]. In the study by Seiler and Hetlelid [26], 12 trained participants completed 6 and 4 min intervals with recovery intervals of different times (1 $\mathrm{min}, 2 \mathrm{~min}$, and $4 \mathrm{~min}$ ), reaching an average HRmax of $179 \mathrm{bpm}$ for intervals of 1 and $2 \mathrm{~min}$ and $178 \mathrm{bpm}$ for $4 \mathrm{~min}$. These values are also similar to those obtained in the present study, possibly due to a greater similarity in the sample and the type of HIT session developed. Regarding the results obtained in the CMJ jump test, no significant differences were observed pre-post-test, nor in the increase in height. This may be because the time between completion of the HIIT protocol and completion of the test may be long enough to restore potential loss of power in subjects. Other factors, in addition to lower extremity strength, affect vertical jump performance, with control of the ability to apply force (coordination) being a key element [27-29]. Regarding the powers during the session, the results found in the present investigation show that when the same total target intensity is used "all out", the three protocols of $30 \mathrm{~s}, 60 \mathrm{~s}$, and $90 \mathrm{~s}$ of work/rest interval produce quite similar results (Figure 5) In the $30 \mathrm{~s}$ protocol, between the first minute and the second minute, there is a loss of $70 \mathrm{w}$, but during the rest of the work, from minute 2 to 10, there are power losses of approximately $40 \mathrm{w}(25 \%)$. In the $60 \mathrm{~s}$ protocol, from the start to the second minute, there is a $90 \mathrm{w}$ power loss. Instead, from the second minute to the end of the test, there was a power loss of $50 \mathrm{w}(24 \%)$.

However, if we compare the mean power maintained (Figure 3) with the studies by Tucker et al. [22], where the mean power maintained was higher for the $16 \times 1$ $(241 \pm 45 \mathrm{~W})$ compared to the $4 \times 4(204 \pm 37 \mathrm{~W})$, there was no significant difference, and Rønnestad et al. [16], with a power during the work intervals of $30 \times 9(363 \pm 32 \mathrm{~W})$ versus $4 \times 5(324 \pm 42 \mathrm{~W})$, also were without difference between their protocols. We observed differences in our study, though, which did obtain differences between the $30 \mathrm{~s}$ and 60 protocols and $30 \mathrm{~s}$ and $90 \mathrm{~s}$, observing possible differences between a short HIIT and a long HIT in terms of powers developed, although there is a greater predisposition to achieve greater power the shorter the work/rest interval. The 3 studies suggest the existence of differences in the nature of the intensity, and differences in work-rest time of the protocols, since Tucker et al. [22] worked at 90-95\% HRmax, but Rønnestad et al. [16], and our study, worked at the maximum intensity that the subject could, although the HIIT work intervals throughout their study have a difference of more than 3 min of work break and $10 \mathrm{~min}$ of total time with ours.

Olney et al. [30] have pointed out that responses to effort during HIIT may be influenced by the length of the interval. Kilpatrick et al. [31] compared perceived exertion responses in HIIT over $30 \mathrm{~s}, 60 \mathrm{~s}$, and $120 \mathrm{~s}$ of maximum intensity work intervals and found that power loss increased from start to finish in all tests, with a greater effect during $120 \mathrm{~s}$. The authors suggested that more frequent rest intervals between the shorter intervals would attenuate the increase in physical exertion, making it "easier" to maintain interval work over time. This is a positive finding because it can help fitness professionals and trainers with more options when prescribing HIIT.

\section{Conclusions}

The results of our research provide practical information for fitness professionals and trainers who prescribe HIIT. Firstly, the nature of the intensity type to be worked on will be a possible factor that can modify the test result, even when the rest of work/rest time 
variables are the same, and secondly, the HIIT of shorter work-rest time intervals allows one to maintain a higher power for a longer time, throughout the work session, without changes in the level of BLa or in the loss of jumping power.

Author Contributions: Conceptualization, F.J.O.-C., P.J.M.-P., A.M.-R. and J.M.G.-D.F.; methodology, F.J.O.-C., P.J.M.-P. and A.M.-R.; software, J.M.G.-D.F. and J.Á.R.-A.; validation, F.J.O.-C. and P.J.M.-P.; formal analysis, J.M.G.-D.F., A.M.-R. and J.Á.R.-A.; investigation, J.M.G.-D.F. and FJ.O.-C.; resources, J.M.G.-D.F., F.J.O.-C. and P.J.M.-P.; data curation, J.M.G.-D.F. and J.Á.R.-A.; writing-original draft preparation, J.M.G.-D.F.; writing—review and editing, F.J.O.-C., P.J.M.-P., J.Á.R.-A. and A.M.-R.; supervision, F.J.O.-C., P.J.M.-P. and A.M.-R.; project administration, F.J.O.-C. All authors have read and agreed to the published version of the manuscript.

Funding: This research received no external funding.

Institutional Review Board Statement: The study was conducted according to the guidelines of the Declaration of Helsinki, and approved by the Ethics Committee of San Antonio Catholic University of Murcia (protocol code C8061811, approval date: 29 June 2018).

Informed Consent Statement: Informed consent was obtained from all subjects involved in the study.

Data Availability Statement: The data presented in this study are available on request from the corresponding author.

Conflicts of Interest: The authors have no conflict of interest to declare.

\section{References}

1. Buchheit, M.; Laursen, P.B. High-intensity interval training, solutions to the programming puzzle: Part I: Cardiopulmonary emphasis. Sports Med. 2013, 43, 313-338. [CrossRef]

2. Azuma, K.; Matsumoto, H. Potential Universal Application of High-intensity Interval Training from Athletes and Sports Lovers to Patients. Keio J. Med. 2017, 66, 19-24. [CrossRef] [PubMed]

3. Gibala, M.J.; Little, J.P.; MacDonald, M.J.; Hawley, J.A. Physiological adaptations to low volume, high intensity interval training in health and disease. J. Physiol. 2012, 590, 1077-1084. [CrossRef]

4. Billat, V.L.; Slawinski, J.; Bocquet, V.; Demarle, A.; Lafitte, L.; Chassaing, P. Intermittent runs at the velocity associated with maximal oxygen uptake enables subjects to remain at maximal oxygen uptake for a longer time than intense but submaximal runs. Eur. J. Appl. Physiol. 2000, 81, 188-196. [CrossRef] [PubMed]

5. Laursen, P.B.; Jenkins, D.G. The scientific basis for high-intensity interval training: Optimizing training programs and maximizing performance in highly trained endurance athletes. Sports Med. 2002, 32, 53-73. [CrossRef] [PubMed]

6. Seiler, S.; Sjursen, J.E. Effect of work duration on physiological and rating scale of perceived exertion responses during self-paced interval training. Scand. J. Med. Sci. Sports 2004, 14, 318-325. [CrossRef]

7. Stølen, T.O.; Høydal, M.A.; Kemi, O.J.; Catalucci, D.; Ceci, M.; Aasum, E.; Larsen, T.; Rolim, N.; Condorelli, G.; Smith, G.L.; et al. Interval training normalizes cardiomyocyte function, diastolic $\mathrm{Ca} 2+$ control, and SR Ca2+ release synchronicity in a mouse model of diabetic cardiomyopathy. Circ. Res. 2009, 105, 527-536. [CrossRef]

8. Tschakert, G.; Hofmann, P. High-intensity intermittent exercise: Methodological and physiological aspects. Int. J. Sport Physiol. Perform. 2013, 8, 600-610. [CrossRef]

9. Hawley, J.A.; Myburgh, K.H.; Noakes, T.D.; Dennis, S.C. Training techniques to improve fatigue resistance and enhance endurance performance. J. Sport Sci. 1997, 15, 325-333. [CrossRef]

10. Hawley, J.A.; Stepto, N.K. Adaptations to training in endurance cyclists: Implications for performance. Sport Med. 2001, 31, 511-520. [CrossRef]

11. Hofmann, P.; Tschakert, G. Special needs to prescribe exercise intensity for scientific studies. Cardiol. Res. Pract. 2010, 2011, 209302. [CrossRef]

12. Weston, K.S.; Wisløff, U.; Coombes, J.S. High-intensity interval training in patients with lifestyle-induced cardiometabolic disease: A systematic review and meta-analysis. Br. J. Sports Med. 2014, 48, 1227-1234. [CrossRef] [PubMed]

13. Follador, L.; Alves, R.C.; Ferreira, S.D.; Buzzachera, C.F.; Andrade, V.S.; Garcia, E.D.; Osiecki, R.; Barbosa, S.C.; Oliveira, L.M.; Silva, S.G. Physiological, Perceptual, and Affective Responses to Six High-Intensity Interval Training Protocols. Percept. Mot. Skills 2018, 125, 329-350. [CrossRef]

14. Seiler, S.; Jøranson, K.; Olesen, B.V.; Hetlelid, K.J. Adaptations to aerobic interval training: Interactive effects of exercise intensity and total work duration. Scand. J. Med. Sci. Sports 2013, 23, 74-83. [CrossRef] [PubMed]

15. Nicol, C.; Avela, J.; Komi, P.V. The Stretch-Shortening Cycle. Sports Med. 2006, 36, 977-999. [CrossRef]

16. Rønnestad, B.R.; Hansen, J.; Vegge, G.; Tønnessen, E.; Slettaløkken, G. Short intervals induce superior training adaptations compared with long intervals in cyclists-An effort-matched approach. Scand. J. Med. Sci. Sports 2015, 25, 143-151. [CrossRef] [PubMed] 
17. Inoue, A.; Impellizzeri, F.M.; Pires, F.O.; Pompeu, F.A.; Deslandes, A.C.; Santos, T.M. Effects of Sprint versus High-Intensity Aerobic Interval Training on Cross-Country Mountain Biking Performance: A Randomized Controlled Trial. PLoS ONE 2016, 11, e0145298. [CrossRef]

18. Almquist, N.W.; Nygaard, H.; Vegge, G.; Hammarström, D.; Ellefsen, S.; Rønnestad, B.R. Systemic and muscular responses to effort-matched short intervals and long intervals in elite cyclists. Scand. J. Med. Sci. Sports 2020, 30, 1140-1150. [CrossRef] [PubMed]

19. American College of Sports Medicine. Position statement on the recommended quantify and quality of exercise for developing cardiorespiratory and muscular fitness in healthy adults. Med. Sci. Sport Exerc. 1998, 22, 265-274.

20. Bosco, C.; Luhtanen, P.; Komi, P.V. A simple method for measurement of mechanical power in jumping. Eur. J. Appl. Physiol. Occup. Physiol. 1983, 50, 273-282. [CrossRef]

21. Cohen, J. Statistical Power Analysis for the Behavioral Sciences, 2nd ed.; Erlbaum: Hillsdale, MI, USA, 1988.

22. Tucker, W.J.; Sawyer, B.J.; Jarrett, C.L.; Bhammar, D.M.; Gaesser, G.A. Physiological Responses to High-Intensity Interval Exercise Differing in Interval Duration. J. Strength Cond. Res. 2015, 29, 3326-3335. [CrossRef]

23. Razenek, R.; Salassi, J.W.; Pinto, N.M.; Fleming, J.D. Acute Cardiopulmonary and Metabolic Responses to High-Intensity Interval Training Protocols Using $60 \mathrm{~s}$ of Work and 60 s Recovery. J. Strength Cond. Res. 2016, 30, 3014-3023. [CrossRef]

24. Schoenmakers, P.J.M.; Reed, K.E. The effects of recovery duration on physiological and perceptual responses of trained runners during four self-paced HIIT sessions. J. Sci. Med. Sport 2019, 22, 462-466. [CrossRef]

25. Stepto, N.K.; Martin, D.T.; Fallon, K.E.; Hawley, J.A. Metabolic demands of intense aerobic interval training in competitive cyclists. Med. Sci. Sports Exerc. 2001, 33, 303-310. [CrossRef] [PubMed]

26. Seiler, S.; Hetlelid, K.J. The impact of rest duration on work intensity and RPE during interval training. Med. Sci. Sports Exerc. 2005, 37, 1601-1607. [CrossRef] [PubMed]

27. Smilios, I.; Pilianidis, T.; Karamouzis, M.; Tokmakidis, S.P. Hormonal responses after various resistance exercise protocols. Med. Sci. Sports Exerc. 2003, 35, 644-654. [CrossRef]

28. Ugrinowitsch, C.; Tricoli, V.; Rodacki, A.L.F.; Batista, M.; Ricard, M.D. Influence of training background on jumping height. J. Strength Cond. Res. 2007, 21, 848-852.

29. Enoka, R.M.; Duchateau, J. Muscle fatigue: What, why and how it influences muscle function. J. Physiol. 2008, 586, 11-23. [CrossRef] [PubMed]

30. Olney, N.; Wertz, T.; LaPorta, Z.; Mora, A.; Serbas, J.; Astorino, T.A. Comparison of Acute Physiological and Psychological Responses Between Moderate-Intensity Continuous Exercise and Three Regimes of High-Intensity Interval Training. J. Strength Cond. Res. 2018, 32, 2130-2138. [CrossRef] [PubMed]

31. Kilpatrick, M.W.; Greeley, S.J.; Collins, L.H. The Impact of Continuous and Interval Cycle Exercise on Affect and Enjoyment. Res. Q. Exerc. Sport 2015, 86, 244-251. [CrossRef] 